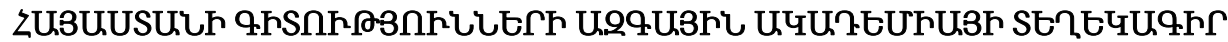 ИЗВЕСТИЯ НАЦИОНАЛЬНОЙ АКАДЕМИИ НАУК АРМЕНИИ
}

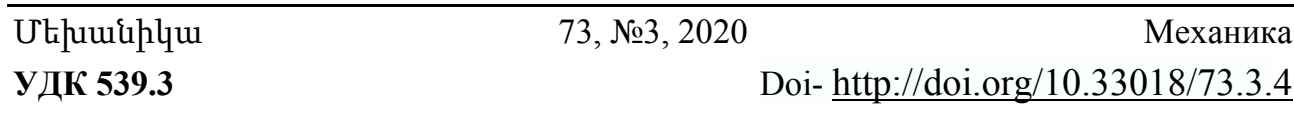

\section{PROPAGATION OF MAGNETOELASTIC WAVES IN A PERIODIC MEDIA Papyan A. A.}

Key words: magetoelastic wave, perfectly conductive, periodic structure.

\section{ПапянА.А. \\ РАСПРОСТРОНЕНИЕ МАГНИТОУПРУГИХ ВОЛН В ПЕРИОДИЧЕСКОЙ СРЕДЕ}

Ключевые слова: магнитоупругие волны, идеальный проводник, периодическая структура.

Рассматривается задача распространения волн в одномерной периодической электропроводящей среде, находящейся во внешнем постоянном магнитном поле. Задача решается на основе теории Флоке.

Установлено влияние внешнего магнитного поля на условия существования запретных зон частот.

Tưu्ujuí U.U.

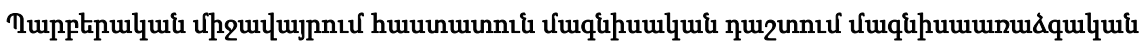
ühpitph unupurnıúp

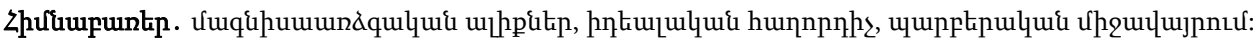

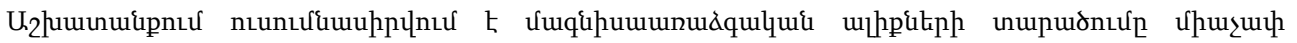

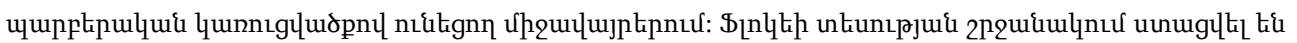

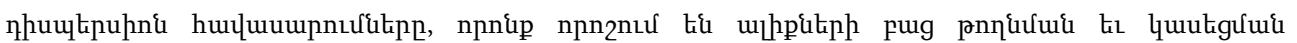

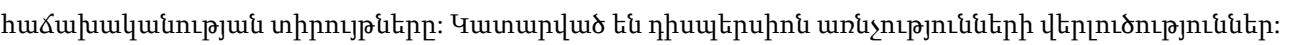

We consider a problem of elastic wave propagation in a perfectly conductive periodic structure in a external magnetic field. In the framework of the Floquet theory the dispersion equations are obtained defining magnetoelastic wave frequency gap bandstructure. The influence of an external magnetic field on the magnetoelasic wave properties and forbidden frequencies arestudied.

\section{Introduction:}

The presence frequency stop or forbidden gaps in a periodic unidirectional elastic structure was first noted in [1]. The detailed studies of elastic wave propagation in a periodic structures are given in $[2-10]$. In the $[6,7,10]$ from a mathematical point of view the Floquet-Bloch waves in elastic periodic waveguides are investigated The spectral theory of transverse vibrations of periodic elastic beams is given in [8-9]. The problems of a magetoelastic wave propagation in electroconducting solid deformable bodies and thin elastic structures are considered in $[11,12]$.

Here we consider a problem of wave propagation in 1D bi-material periodic structure consisting of periodically alternating perfectly conductive materials in an external constant 
magnetic field. We will investigate the effect of magnetic field on the properties of the magnetoelastic wave propagation in periodic structure.

\section{The statement of problem:}

The purpose of this paper is to investigate properties of magnetoelastic waves in an1D infinite periodic elastic structure in an external constant magnetic field. The unit cell of a period $d$ consists of two piecewise elastically bonded perfect conducting homogeneous materials (Figure 1).

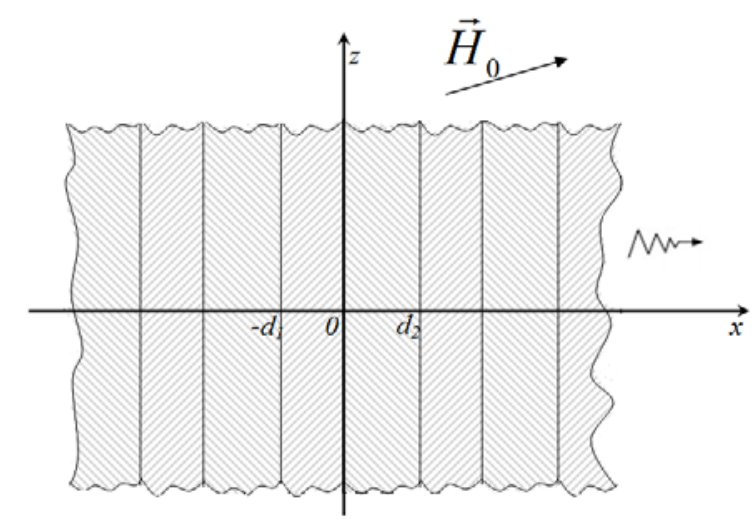

Fig. 11D periodic electro conductive elastic structure in an external constant magnetic field $\vec{H}_{0}$.

The structure of a periodically repeating unit cellare characterized by the material density and the modulus of elasticity as follows:

$\rho_{1}, E_{1} \rightarrow-(n-1) d-d_{1}<x<(n-1) d$,

$\rho_{2}, E_{2}, \rightarrow(n-1) d<x<n d-d_{1}$

In the rectangular Cartesian coordinate system $0 x y z$ axis $x$ is directed along wave direction, when axis $z$ can be chosen so, that the displacements to the axis $x$ the component of the magnetic field coincide with the axis $z$, when $\vec{H}_{0}=H_{0 x} \vec{i}+H_{0 z} \vec{k}$

The pondermotive force vector for a perfect conductive material is as follows [11].

$\vec{R}=\frac{\mu}{4 \pi}\left\{\operatorname{rot} \operatorname{rot}\left(\vec{u} \times \vec{H}_{0}\right)\right\} \times \vec{H}_{0}$

where $\vec{u}$ is the vector of elastic displacement, $\mu$ magnetic permeability of the material.

The components of ponderomotive force vectorare as follows: 


$$
\begin{aligned}
& R_{x}=\frac{\mu}{4 \pi}\left(\frac{\partial^{2} u}{\partial x^{2}} H_{0 z}^{2}-\frac{\partial^{2} w}{\partial x^{2}} H_{0 x} H_{0 z}\right), \quad R_{y}=\frac{\mu}{4 \pi} \frac{\partial^{2} v}{\partial x^{2}} H_{0 x}^{2} \\
& R_{z}=\frac{\mu}{4 \pi}\left(\frac{\partial^{2} w}{\partial x^{2}} H_{0 x}^{2}-\frac{\partial^{2} u}{\partial x^{2}} H_{0 x} H_{0 z}\right)
\end{aligned}
$$

According to the Floquet theory, we consider solutions only in the elementary cell $-d_{1}<x<d_{2} \quad(n=1)$, applying the Floquet-Bloch quasi-periodicity conditions at the ends of the elementary cell.

The motion equation in for $1 \mathrm{D}$ waves can be written in the following form

$$
\frac{\partial \sigma_{11}}{\partial x} R_{x}=\rho \frac{\partial^{2} U_{1}}{\partial t^{2}}, \frac{\partial \sigma_{12}}{\partial x}+R_{y}=\rho \frac{\partial^{2} U_{2}}{\partial t^{2}}, \frac{\partial \sigma_{13}}{\partial x}+R_{z}=\rho \frac{\partial^{2} U_{3}}{\partial t^{2}}
$$

where $\sigma_{i j}$ are components of stress tensor.

The motion equation(2) in displacements in the interval $-d_{1}<x<d_{2}, \quad(n=1)$ can be written as

$$
\begin{aligned}
& c_{l(s)}^{2} \frac{\partial^{2} u_{(s)}}{\partial x^{2}}+\frac{\mu_{(s)}}{4 \pi \rho_{(s)}}\left(\frac{\partial^{2} u_{(s)}}{\partial x^{2}} H_{0 z}^{2}-\frac{\partial^{2} w_{(s)}}{\partial x^{2}} H_{0 x} H_{0 z}\right)=\frac{\partial^{2} u_{(s)}}{\partial t^{2}} \\
& c_{t(s)}^{2} \frac{\partial^{2} w_{(s)}}{\partial x^{2}}+\frac{\mu_{(s)}}{4 \pi \rho_{(s)}}\left(\frac{\partial^{2} w_{(s)}}{\partial x^{2}} H_{0 x}^{2}-\frac{\partial^{2} u_{(s)}}{\partial x^{2}} H_{0 x} H_{0 z}\right)=\frac{\partial^{2} w_{(s)}}{\partial t^{2}}
\end{aligned}
$$

where indexes $s=1,2$ characterize materials of periodic structure $c_{l}^{2}, c_{t}^{2}$ are the speeds of the longitudinal and transversal waves, correspondingly.

We have the conditions of elastic contact on the boundary of separation of materials

$$
\begin{aligned}
& u_{(1)}(0, t)=u_{(2)}(0, t), \quad w_{(1)}(0, t)=w_{(2)}(0, t), \\
& \sigma_{x x(1)}(0, t)+t_{x x(1)}(0, t)=\sigma_{x x(2)}(0, t)+t_{x x(2)}(0, t), \\
& \sigma_{x z(1)}(0, t)+t_{x z(1)}(0, t)=\sigma_{x z(2)}(0, t)+t_{x z(2)}(0, t),
\end{aligned}
$$

and the Floquet quasi-periodicity conditions

$$
\begin{aligned}
& u_{(1)}\left(-d_{1}, t\right)=\lambda u_{(2)}\left(d_{2}, t\right), \quad w_{(1)}\left(-d_{1}, t\right)=\lambda w_{(2)}\left(d_{2}, t\right), \\
& \sigma_{x x(1)}\left(-d_{1}, t\right)+t_{x x(1)}\left(-d_{1}, t\right)=\lambda\left(\sigma_{x x(2)}\left(d_{2}, t\right)+t_{x x(2)}\left(d_{2}, t\right)\right), \\
& \sigma_{x z(1)}\left(-d_{1}, t\right)+t_{x z(1)}\left(-d_{1}, t\right)=\lambda\left(\sigma_{x z(2)}\left(d_{2}, t\right)+t_{x z(2)}\left(d_{2}, t\right)\right),
\end{aligned}
$$

Here $\lambda=\exp (i k d), k$ - Floquet's wave number. 
$t_{x x}, t_{x z}$ are components of the Maxwell tensor, that are as follows[11]:

$t_{x x(s)}=\frac{\mu_{(s)}}{4 \pi}\left(\frac{\partial u_{(s)}}{\partial x} H_{0 z}^{2}-\frac{\partial w_{(s)}}{\partial x} H_{0 x}^{2}\right)$

$t_{x z(s)}=\frac{\mu_{(s)}}{4 \pi}\left(\frac{\partial w_{(s)}}{\partial x} H_{0 x}^{2}-\frac{\partial u_{(s)}}{\partial x} H_{0 x} H_{0 z}\right)$

Presenting solutions of equations (3) and (4) in the form

$u_{1}(x, t)=u_{10}(x) \exp (i \omega t), u_{2}(x, t)=u_{20}(x) \exp (i \omega t)$,

$w_{1}(x, t)=w_{10}(x) \exp (i \omega t), \quad w_{2}(x, t)=w_{20}(x) \exp (i \omega t)$,

We have

$u_{(s) 0}^{\prime \prime}-p_{(s)} w_{(s) 0}^{\prime \prime}+q_{(s)} u_{(s) 0}=0$

$u_{(s) 0}^{\prime \prime}-\alpha_{(s)} p_{(s)} w_{(s) 0}^{\prime \prime}+\alpha_{(s)} q_{(s)} u_{(s) 0}=0$

Here the following notations are made:

$$
\begin{aligned}
& a_{3(s)}^{2}=\frac{\mu_{(s)}}{4 \pi \rho_{(s)}} H_{0 z}^{2}, a_{1(s)}^{2}=\frac{\mu_{(s)}}{4 \pi \rho_{(s)}} H_{0 x}^{2}, a_{3(s)}, a_{1(s)}=\frac{\mu_{(s)}}{4 \pi \rho_{(s)}} H_{0 x} H_{0 z} \\
& \alpha_{(s)}=\frac{c_{l(s)}^{2}+a_{3(s)}^{2}}{c_{t(s)}^{2}+a_{1(s)}^{2}}, p_{(s)}=\frac{a_{3(s)} a_{1(s)}}{c_{l(s)}^{2}+a_{3(s)}^{2}}, q_{(s)}=\frac{\omega^{2}}{c_{l(s)}^{2}+a_{3(s)}^{2}} ;
\end{aligned}
$$

The solutions of the differential system equations (10) satisfying the conditions of elastic contact and on the boundary of separation materials and the Floquet conditions, we obtain the dispersion equation for

$$
\cos (k d)=F\left(\eta, H_{01}, H_{03}\right)
$$

The dispersion equation (12) determines the wave number $k$ depending on the frequency of $\eta$ (non dimensionless frequency) and external magnetic field.

\section{Special case:}

Let consider a special case when the magnetic field is directed along the axis $Z$, $\vec{H}_{0}=H_{0 z} \vec{k}$

In this case the system of differential equations are separated from each other regard to and we have only one the electro-magneto active equation regard to longitudinal displacement $u_{(s) 0}$. 
If magnetic field is directed perpendicular to wave propagation direction we will have the electro-magneto active equation regard to transversal displacement $w_{(s) 0}$.

We consider now the equation

$$
u_{(s) 0}^{\prime \prime}+q_{(s)} u_{(s) 0}=0
$$

with the conditions of elastic contact on the boundary of separation of materials:

$$
\begin{aligned}
& u_{(1)}(0, t)=u_{(2)}(0, t), \\
& \sigma_{x x(1)}(0, t)+t_{x x(1)}(0, t)=\sigma_{x x(2)}(0, t)+t_{x x(2)}(0, t),
\end{aligned}
$$

and Floquet quasi-periodicity conditions

$$
\begin{aligned}
& u_{(1)}\left(-d_{1}, t\right)=\lambda u_{(2)}\left(d_{2}, t\right), \\
& \sigma_{x x(1)}\left(-d_{1}, t\right)+t_{x x(1)}\left(-d_{1}, t\right)=\lambda\left(\sigma_{x x(2)}\left(d_{2}, t\right)+t_{x x(2)}\left(d_{2}, t\right)\right),
\end{aligned}
$$

The solutions of differential equation (13) can be written as:

$$
\begin{aligned}
& u_{10}(x)=\left(B_{1} \sin \left(\sqrt{q_{1}} x\right)+B_{2} \cos \left(\sqrt{q_{1}} x\right)\right) \\
& \sigma_{10}(x)=\tilde{E}_{1} \sqrt{q_{1}}\left(B_{1} \cos \left(\sqrt{q_{1}} x\right)-B_{2} \sin \left(\sqrt{q_{1}} x\right)\right) \\
& u_{20}(x)=\left(C_{1} \sin \left(\sqrt{q_{2}} x\right)+C_{2} \cos \left(\sqrt{q_{2}} x\right)\right) \\
& \sigma_{20}(x)=\left(\lambda_{2}+2 G_{2}\right) \sqrt{q_{2}}\left(C_{1} \cos \left(\sqrt{q_{1}} x\right)-C_{2} \sin \left(\sqrt{q_{1}} x\right)\right)
\end{aligned}
$$

where $\tilde{E}_{(s)}=\lambda_{(s)}+2 G_{(s)}, \lambda, G$ are Lameconstants.

Satisfying the solution (14) conditions of the elastic contact on the line of separation materials and Floquet condition, we obtain homogeneous system equations regard to constants $B_{1}, B_{2}, C_{1}, C_{2}$.

Equating to zerothe determinant of this system, we obtain the following dispersion equation

$$
\begin{aligned}
& \cos (k d)=\cos \left(d_{1} \sqrt{q_{1}}+d_{2} \sqrt{q_{2}}\right) \\
& -\frac{1}{2}\left\{\frac{\tilde{E}_{1}+\frac{\mu_{1} H_{03}^{2}}{4 \pi}}{\tilde{E}_{2}+\frac{\mu_{2} H_{03}^{2}}{4 \pi}} \frac{\sqrt{q_{1}}}{\sqrt{q_{2}}}+\frac{\tilde{E}_{2}+\frac{\mu_{2} H_{03}^{2}}{4 \pi}}{\tilde{E}_{1}+\frac{\mu_{1} H_{03}^{2}}{4 \pi}} \frac{\sqrt{q_{2}}}{\sqrt{q_{1}}}\right\} \sin \left(d_{1} \sqrt{q_{1}}\right) \sin \left(d_{2} \sqrt{q_{2}}\right)
\end{aligned}
$$

Let note that when magnetic field is directed perpendicular to wave propagation direction we get the same dispersion equation changing $c_{l(s)} \rightarrow c_{t(s)}$. 


\section{Discussions and numerical results:}

The dispersion equations (17) define ranges of frequencies associated with waves that can propagate in perfectly conductive periodic solid (pass bands), alternated with ranges of frequencies of waves that cannot be transmitted (stop band gaps).

In the case when the material electromagnetic impedances are equal $\left(\tilde{E}_{1}+\frac{\mu_{1} H_{0 z}^{2}}{4 \pi}\right) \sqrt{\frac{1}{c_{l 1}^{2}+a_{3(1)}^{2}}}=\left(\tilde{E}_{2}+\frac{\mu_{2} H_{0 z}^{2}}{4 \pi}\right) \sqrt{\frac{1}{c_{l 2}^{2}+a_{3(2)}^{2}}}$

we have

$$
\cos (k d)=\cos \left(d_{1} \sqrt{q_{1}}+d_{2} \sqrt{q_{2}}\right)
$$

which means that in this case the stop band gaps donot occur.

When the magnetic field is vanished we get the classic result considered in [2]:

The dispersion curves $\eta(k d)$ of dimensionless frequency $\eta=\omega d_{1} c_{l 2}^{-1}$ in the first Brillouin zone $0<k d<\pi$ defining the stop band gaps, are illustrated in the Fiqure.2, Fiqure. 3 for certain values of dimensionless parameters.

$$
\alpha^{2}=\frac{a_{3(1)}^{2}}{c_{l(1)}^{2}}, \quad \gamma=\frac{c_{l(1)}^{2}}{c_{l(2)}^{2}}, \quad \beta=\frac{a_{3(2)}^{2}}{a_{3(1)}^{2}}, \quad \theta=\frac{d_{2}}{d_{1}}, \quad \zeta=\frac{\rho_{1}}{\rho_{2}} ;
$$

characterizing mechanical and geometric properties of periodic structure and the magnitude of the external magnetic field. The dashed curves correspond to magnetoelastic case, the solid curves correspond to the classic elastic case.

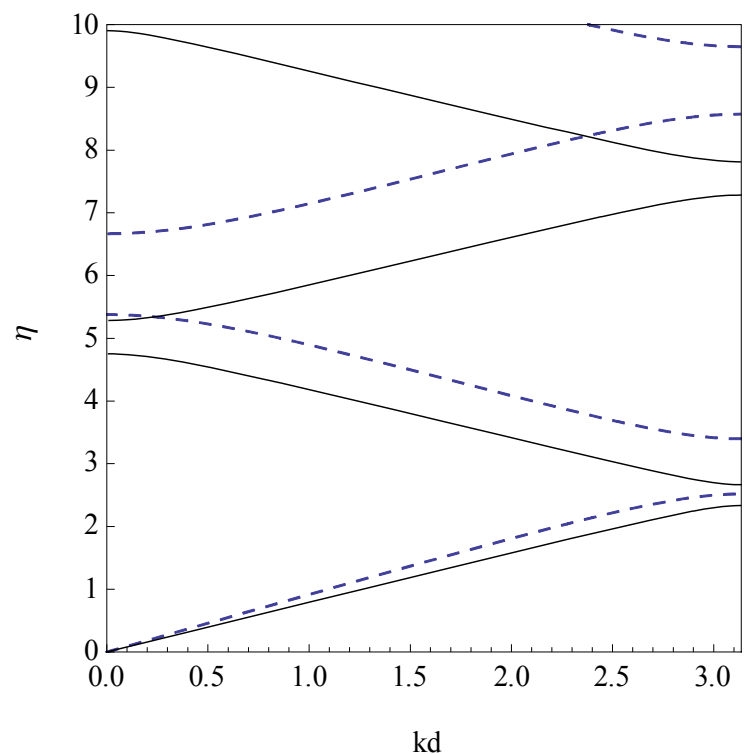


Fig1. Dispersion curves $\eta(k d), \alpha=0.75 ; \quad \xi=0.5 ; \quad \beta=0.55 ; \quad \gamma=0.25 ; \theta=0.25$

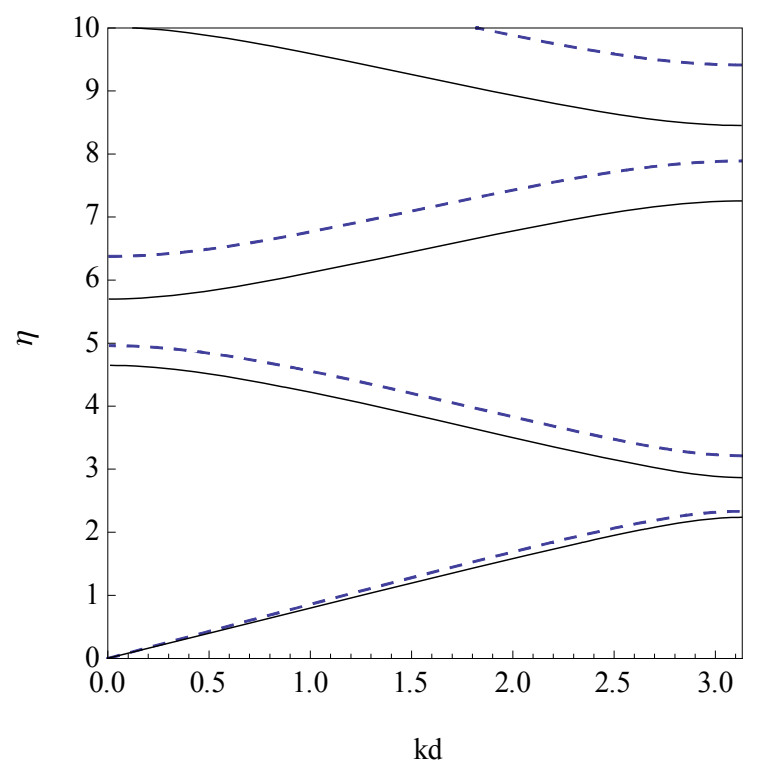

Fig. 2 Dispersion curves $\eta(k d), \alpha=0.5 ; \xi=0.5 ; \beta=0.25 ; \quad \gamma=0.2 ; \theta=0.2$

Analysis of the dispersion curves shows that the external magnetic field change the position and essentially diminish the width of band gaps.

Conclusions:In the framework of the magneto-elasticity equationsand the Floquet theory the magnetoelasic wave propagation in 1D perfectly conductive piecewise periodic media is studied.The corresponding dispersion equation are obtained in the case when the direction of magnetic field is perpendicular to the wave propagation direction. The dispersion curves illustrating the magneto elastic wave properties are presented.Analysis of the dispersion curves in thefirst Brillouinzone shows that the external magnetic field essentially change the positions and diminish the widths of band gaps.

Acknowledgement: This work was supported by the RA MES Science Committee, in the frames of the research project № 19YR-2C044.

\section{Literature}

1. Lord Rayleigh, On the maintenance of vibrations of forces of double frequency, and on the propagation of waves through a medium endowed with a periodic structure, Phil. Mag., 24 (1887), pp. 145-159.

2. E.H. Lee, A survey of variational methods for elastic wave propagation analysis in composites with periodic structures, in Dynamics of Composite Materials, E. H. Lee, ed., ASME, New York, 1972, pp. 122-138.

3. E.H. Lee and W. H. Yang, On waves in composite materials with periodic structure, SIAM Journal on Applied Mathematics., 25 (1973), pp. 492-499.

4. Mingrong Shen, Wenwu Cao, Acoustic bandgap formation in a periodic structure with multilayer unit cells, Journal Phys. D: Appl. Phys. 33 , (2000), p.1150-1154 
5. A.Velo, E. Bruder, N. Rodriguez, G. Gazonas, E. Bruder, Recursive Dispersion Relations in One-Dimensional Periodic Elastic Media, SIAM Journal on Applied Mathematics, Vol. 69, No. 3, pp. 670-689, (2008).

6. S.Adams, R. Craster, S. Guenneau, Bloch waves in periodic multi-layered acoustic waveguides, Proceedings Royal Society London A 464 (2008) p.2669-2692,

7. R.V. Craster, S. Guenneau, S. Adams, Mechanism for slow waves near cutoff frequencies in periodic waveguides, Physical Review B, 2009 79, p.045129-5,

8. V.G. Papanicolaou, The periodic Euler-Bernoulli equation, Trans. AMS 355 (2003), $3727-3759$.

9. V.G. Papanicolaou,An Inverse Spectral Result for the Periodic Euler-Bernoulli Equation, Indiana University Mathematics Journal (2004), Volume: 53, Issue: 1, Pages: 223-242.

10. Аветисян А.С., Казарян К.Б. Волны в “фонон-фотон” кристаллах и импеданс. В сб. "Проблемы механики деформируемого твердого тела" посвящ. 90-летию академика НАН Армении С.А. Амбарцумяна. Ереван. 2012. с.15-22.

11. Багдасарян Г.Е., Даноян 3.Н. Электромагнитоупругие волны. Изд. Ереванского Университета, Ереван, 2006. с. 491.

12. Амбарцумян С.А., Белубекян М.В. Колебания и устойчивость токонесуших упругих пластин.- Ереван, изд-во АН Армения, 1992, 123с.

13. Амбарцумян С. А., Багдасарян Г. Е., Белубекян М. В. Магнитоупругость тонких оболочек и пластин. -М., Наука, 1977, с.272.

\section{Information about author:}

Papyan Ararat Arthur, Researcher at the Institute of Mechanics NAN RA. Address: Yerevan ave. Marshal Baghramyan 24b, 0019, Yerevan, Armenia. E-mail: papyanararat11@gmail.com

Received 05.07.2020 